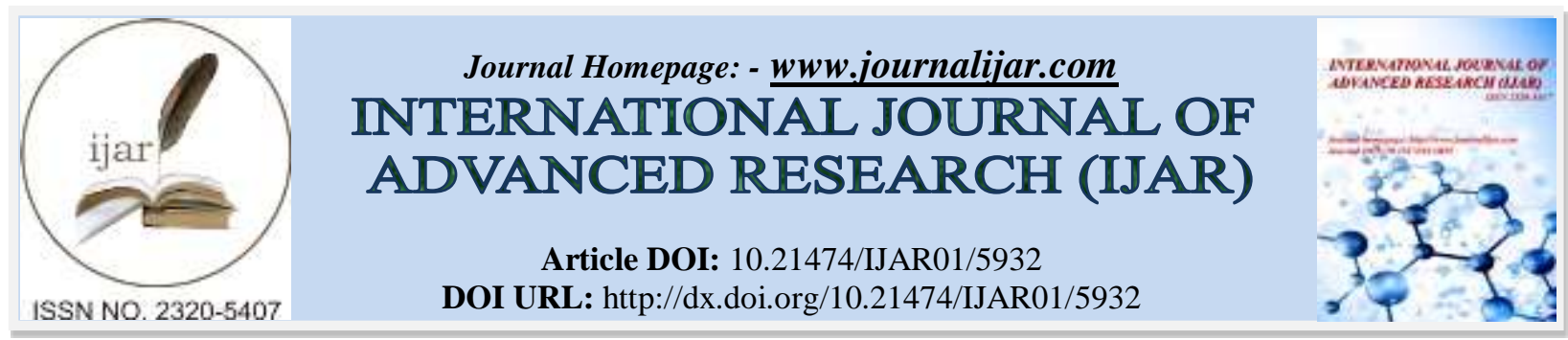

RESEARCH ARTICLE

\title{
SOIL MOISTURE BASED IRRIGATION TEST IN A REMOTELY MONITORED AUTOMATED SYSTEM.
}

Ronny Gorata Matenge.

Department of Water Engineering, Pan African University Institute of Water and Energy Sciences (including Climate Change) PAUWES.

\section{Manuscript Info}

Manuscript History

Received: 01 October 2017

Final Accepted: 03 November 2017

Published: December 2017

Key words:-

Soil Moisture Sensor, solar system, microcontroller, GSM modem, Automated Irrigation System.

\section{Abstract}

The proposed paper aims at determining the most efficient soil moisture monitoring method in an intelligent remotely monitored system. The project also demonstrates the economic viability of an integrated system of production were water requirement, nutrients and $\mathrm{pH}$ are kept optimum automatically. The system is designed to overcome the challenges of water wastage, nutrition deficit, $\mathrm{pH}$ imbalance and leaching of nutrients. This system is powered by Solar System, controlled by Microcontroller and programmed using LabVIEW Software. The Microcontroller is connected GSM (Global System for Mobile communication) wireless network, which allows the system to communicate with the farmer remotely using a mobile phone. This proposed smart farming technology is environmentally friendly, efficient, cost effective and gives the farmer the power to control and monitor production in real time

Copy Right, IJAR, 2017,. All rights reserved.

\section{Introduction:-}

Botswana's agricultural sector be highly affected by climatic variations because of increased temperatures, reduced rainfall and the frequent occurrence of drought. Horticulture industry is mainly constrained by water shortage due to the dependence on seasonal unreliable rainfall and poor farm management practices (Madisa, 2012). These challenges threaten food security of the country since it heavily relies of imported foods products. Climate change will reduce the quality and quantity of exported goods due to reduced agricultural surplus. Agricultural purposes uses 85\% of available fresh water (Venkatraman, Kumar, Anish, Abinesh, \& Bennet, 2016), the demand for food and water consumption will continue to increase as long as population increases.

Major part of the country remains unproductive mainly due to poor sandy soil and deeper aquifers of the Kalahari Desert. Despite having abundance of sunlight, the source of energy remains untapped. In addition, high power/fuel cost and long distances to the market have increased the cost production. Despite the challenges of water shortages, over-irrigation is a problem attributed to inadequate irrigation scheduling and moisture content monitoring. Poor traditional practices of irrigation like low frequency and high volumes irrigation usually results in inefficient water use. Improved irrigation efficiency can make the vegetable industry more competitive and sustainable as a result the production cost will be low (Schroder, 2006). The irrigation management practices are designed to avoid moisture stress with little water while maximizing yield. Increased labour costs, stricter Eco-friendly regulations and

Corresponding Author:- Ronny Gorata Matenge.

Address:- Department of Water Engineering, Pan African University Institute of Water and Energy

Sciences (including Climate Change) PAUWES. 
increased competition for water resources from urban areas is a wakeup call to provide more efficient Irrigation system (Dhanure \& Avatade, 2015).

In order to overcome these challenges, farmers need to be equipped and updated with new improved production practices through research and extension services strategies that are climate smart. Solar energy remains the most reliable, renewable environmental friendly source of energy, which needs to be integrated into modern day farming technologies. Automated drip irrigation system has proven to be water efficient in optimizing agricultural production. Fertigation process allows fertilizer to be applied at the root zone in the right proportion through the irrigation system. Irrigation and fertigation management is one of the main determining factor of quality and productivity in agribusiness (Gómez-melendez et al., 2011). The advancement of technology has allowed development of various methodologies for monitoring soil moisture status automatically to irrigate without human intervention (Dhanure \& Avatade, 2015). This research proposes a system has great capacity in water savings compared to traditional methods of irrigation scheduling and fertilization.

Intelligent smart farming system is such that $\mathrm{pH}$ control, nutrient supply and plant water requirement supply is monitored and adjusted automatically through use of sensors and closed-loop feedback system. Further work by (Rahali et al., 2011) supports this claim that electronic system achieves the control and remote monitoring of greenhouse solutions, in particular drip irrigation stations. This system uses a preprogrammed setup to collect real time data in the environment through sensors. Modern irrigation incorporates the use of Micro controller mechanism, which give the farmer real time update on irrigation activities. This automation technology has closedloop feedback mechanism were soil $\mathrm{pH}$, fertigation and soil moisture content is controlled, monitored and adjusted accordingly.

This project proposes a research on the experimentation and development of a fully automated moisture based irrigation system, nutrient solution application and monitoring of $\mathrm{pH}$ using a computerized feedback loop system in open field. There is need to measure the efficiencies of calibrate sensors, tensiometers, and dielectric probe in monitoring soil moisture efficiently and effectively. The irrigation will be carried out according to the moisture content deficit and compare the yields per unit area for the different devices. The core reason for irrigating according to moisture content deficit is to maintain the optimum amount of moisture the plant requires and still retain the same or increase yield while cutting costs of production.

This project powered is by sustainable, renewable solar power system, which offers sufficient and effective energy for farmers at low cost. The system will use microcontroller, LabVIEW software for the interface connected to a PC for monitoring and GSM (Global System for Mobile communication) for remote communication with the system which is convenient for farmers through text SMS. The setup is selected for its real time, user friendliness, flexibility and availability at low cost (Rahali et al., 2011). Moisture sensors which are considered to be the most efficient instruments for their real time moisture monitoring will be incorporated. The technology allows users uses smart mobile to control farm field activities through wireless network. The main aim of this project is to demonstrate the economic feasibility of advanced computerized production technologies.

\section{Objectives:-}

To automatically optimize use of water in food production through soil moisture based irrigation system

\section{Specific objectives:-}

- To determine the efficiencies of moisture measuring instrument

- To calibrate sensors, tensiometers, and dielectric probe to measure moisture content

- To automatically measure and adjust plant growth parameters using closed-loop feedback mechanism

\section{Problem Statement:-}

Water is a scarce resource, $85 \%$ of it is used in agriculture through irrigation. Inefficiencies in irrigation and fertilizer application has resulted in increased production cost and lower production in farms. Knowing when, where and how much water and nutrient solution to apply at appropriate $\mathrm{pH}$ is the important aspects of horticulture farming. Computerized control in inputs application has been found to be efficient and effective approach to address these challenges. 


\section{Literature Review:- \\ Background information:- \\ Climate: Water/ rainfall, Soil and Topography:-}

The Kalahari Desert covers about two thirds of the country, which is mainly sandy soil with a depth of about $120 \mathrm{~m}$ and a topography of $1000 \mathrm{~m}$. Rainfall is scarce; the only source of water is underground fossil aquifers obtained by drilling boreholes, which can be up to $500 \mathrm{~m}$ deep. The eastern side is mainly sandy loams to clay loams with a low topography of $500 \mathrm{~m}$ draining rich alluvial soils into the Limpopo valley. Rainfall is low and unevenly distributed. Mean rainfall is $650 \mathrm{~mm}$ in the northeast, 550 in southeast and $250 \mathrm{~mm}$ in the southwestern part (Burgess, 2006). These water scarcity conditions needs stringent farming techniques to be adopted if the country is to become selfsufficient it food production.

\section{Energy:}

There is a relationship between energy and development of any economic sector of every country (Essah \& Ofetotse, 2014). Botswana is currently under capacitated in energy production, producing only $30 \%$ of its power while $70 \%$ is imported from South Africa (Eskom). According to Gases, (2012) 17\% of farmers have access to electricity which call for a need to use alternatives like solar energy.

\section{Food:}

In 2014 Botswana imported \$564 million worth of food products (FAO, 2015). The national demand for vegetables in 2008/09 was estimated to be 50000 tons comparative to local production which was only 3100 tons (Madisa, 2012). According to ("STATISTICS BOTSWANA GROSS DOMESTIC PRODUCT," 2017) fruits and vegetable production decreased by $19.5 \%$ in 2016 . Only 2000 ha are equipped for irrigation. This alone is an interpretation of incapacity in levels of production, in our country.

\section{The Control System:}

Various studies has been done in recent years on automatic irrigation and soil moisture monitoring technology mostly in greenhouses (Salleh et al., 2013). The system entail use of soil moisture sensors and actuators, which collect data and send it to micro controller for interpretation. The micro controller the sends the data to Personal computer or an android mobile phone for real time monitoring and controlling activities by the farmer. Graphical user interfaces (GUI) uses LabVIEW that was designed to acquire and monitor different climatic conditions. This allows the user/farmer to control farming activities from anywhere automatically without manual labour intervention (Dhanure \& Avatade, 2015) ; (Rahali et al., 2011). Zigbee wireless network is mostly used in greenhouse for monitoring and controlling system environmental parameters. It mainly includes greenhouse remote monitoring and control software; and greenhouse data acquisition controller (Jianjun, Xiaofang, Xiu, Wei, \& Jichen, 2013). Global System for Mobile Communications (GSM) technology has been used to share information between the farmer and the computer control system wirelessly through text message (Barsoum \& Peter, 2015). It has to be noted that Zigbee wireless network is limited to only $1.5 \mathrm{~km}$ between the monitoring center and the greenhouse controller. Wireless sensor network (WSN) has also been used in Asia to monitor environmental parameters in greenhouses. It has been adopted because of its simplicity and low cost in installation and maintenance (Salleh et al., 2013). Fuzzy controller make use of feedback sensors and computer preprogrammed parameters to control the flow of fertilizer solutions, nutrient solutions and acid/base solutions. It works by measuring the amount of solution flowing out through flow meters operated by pumps and proportional valves(Gómez-melendez et al., 2011).

\section{Soil Moisture Monitoring:}

Irrigating the right amount of water at the right time if key to quality produce and efficient irrigation (Barsoum \& Peter, 2015). Advancement of technology has made automated soil moisture monitoring devices available for more efficient irrigation operations. Soil moisture based scheduling combined with drip irrigation and fertigation system was found to be very effective. It saves up to $70 \%$ of water compared to time based schedule system and has high potential of reducing fertilizer loss due to leaching. Their efficiencies depends on correct calibration to match a specific soil type. Schroder (2006) found out that employing switching tensiometers provided $71 \%$ water savings over the time-based treatment, and the dielectric probe achieved $83 \%$. For time based irrigation maximum daily needs for autumn is $2.5 \mathrm{~mm} /$ day calculated from historical weather data $(\mathrm{ETo}=2.79 \mathrm{~mm} / \mathrm{day})$ and crop coefficients $(\mathrm{Kcmax}=0.9)($ Schroder, 2006). 


\section{Irrigation and Fertigation:}

Irrigation water is pumped in accordance to plant water requirement that can be sustained by the pipes. Solenoid valves control rate of flow. The valves are controlled remotely by text instructions using SMS (Rahali et al., 2011). Sustainability of vegetable production requires optimization of fertilizer and water use to maintain high yields and profitability. Venturi has proven to be a cheap and accurate method of fertilizer application. Schroder (2006) (Schroder, 2006) conducted an experiment applying IFAS recommended fertilizer rates for a tomato crop using Venturi injectors (model no. 484, Mazzei Injector Corp., Bakersfield, CA). In his experiment, he used lysimeter in an area of $0.170 \mathrm{~m}^{2}$ to capture leachate. Moisture based irrigation saves over $79 \%$ of phosphorus compared to time based irrigation. The discovery showed that there is no significant difference in marketable yield for all the treatments whereas the amount of water varied significantly. This paper seek to find the most efficient soil moisture monitoring devices (sensors, tensiometers, and dielectric probe) comparable to traditional time based irrigation scheduling.

\section{Research gap:-}

1. Almost all the soil monitoring devices and control system was done in green houses. This project will apply it in open field.

2. The researches are mainly done in Asian and Western countries not Africa. This research will be conducted in Africa particularly in Botswana were environmental conditions are very different.

3. There is no research done on comparing the efficiencies of sensors, tensiometers, and dielectric probe to measure moisture content

\section{Methodology:-}

\section{System Overview:-}

The proposed system is composed of the following components: solar system, microcontroller, solenoid valves, sensors, tensiometers, dielectric probe, $\mathrm{pH}$ sensors and the fertigation system. The entire system will be power by solar power, which store excess power into a $12 \mathrm{~V}$ battery for use when there is limited sunlight. Moisture instruments collect data from the field, send it to the micro controller. Micro controller constantly monitors the various sensors and verifies them with the predefined threshold values. It checks if any corrective action is to be taken for values that are over the setting range by switching on the appropriate device at that instant of time (Hsing, Yu, \& Jenq, 2011), (Alausa \& Kolawole, 2013). The information is then displayed in LCD. LabVIEW Software to be stimulated into a computer software then loaded into the microcontroller. Analog to Digital Converter (ADC) is used to convert voltage from sensors to digital form so that they can be displayed in the LCD Display. Signals and data is collected, processed and saved in a Microsoft excel.

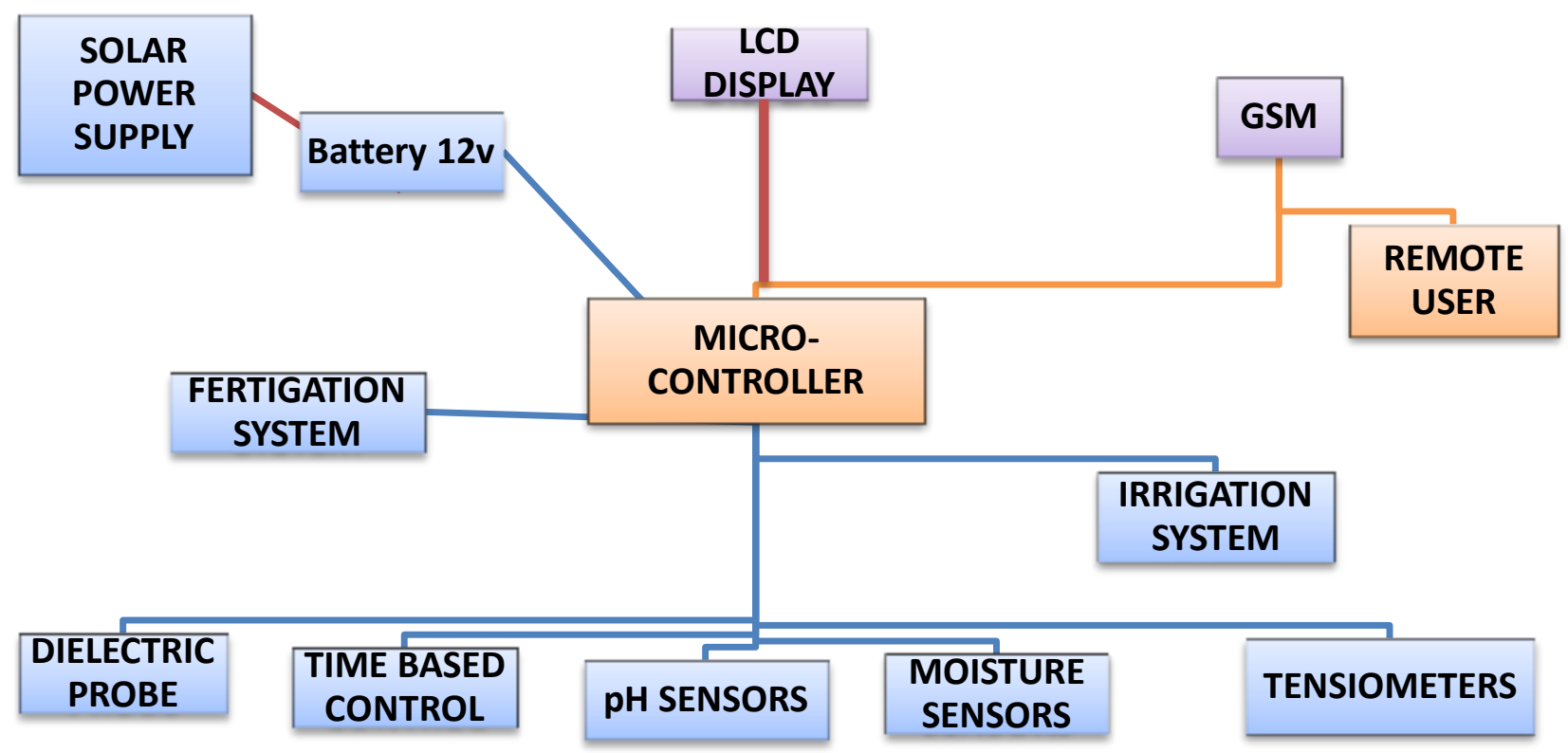

Figure 1:- System overview 
GSM modem:-

GSM (Global System for Mobile communication) make use of GSM wireless network, which incorporate Subscriber Identity Module (SIM) card responsible for sending and receiving text messages.

pH of soil:-

A calibrated soil $\mathrm{pH}$ sensors record directly $\mathrm{pH}$ range in the soil and send signal to the micro controller when the has dropped or gone beyond the limit range. When the $\mathrm{pH}$ has become more acidic or alkaline the micro controller sends signal to solenoid valves to open and close the suitable solution until the suitable adjustment has been made. This is important parameter since plants can only absorb nutrients between 6.5 and 7.5 range on a pH meter.

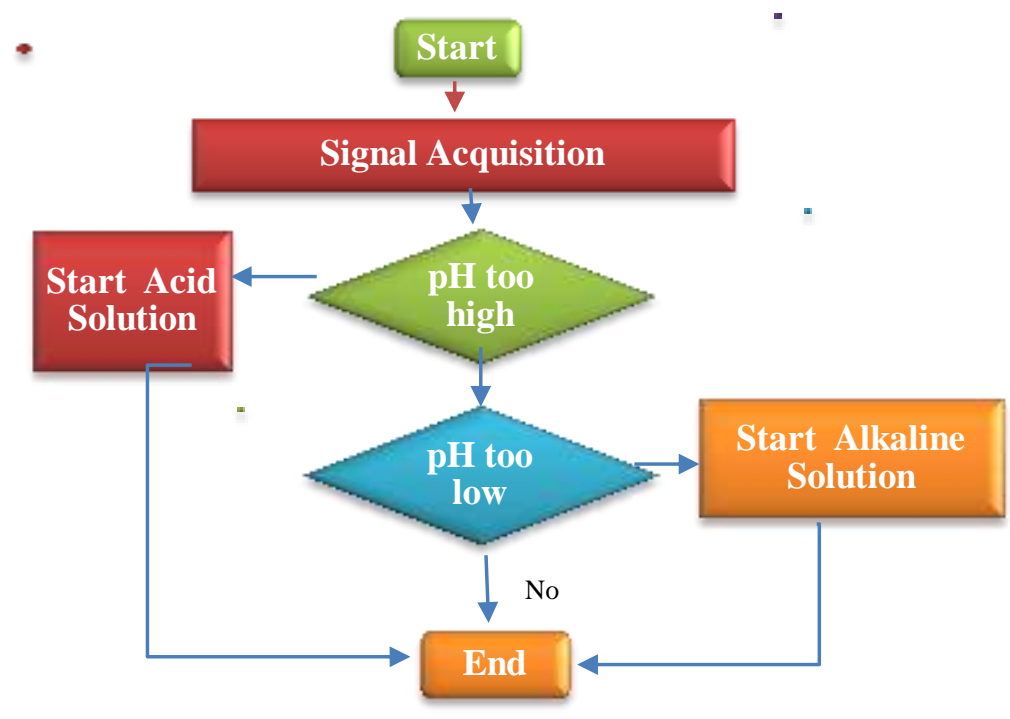

Figure 2:- $\mathrm{pH}$ control Flow

Soil Moisture Content:-

Soil moisture content is the single most important factor determining plant growth. The proposed system is going to test the efficiency of Dielectric Probe, Moisture Sensors, and Tensiometers in comparison to Time Based method. The moisture measuring devices are programmed such that they detect arrange of moisture content and send signal to the microcontroller accordingly. The micro controller will check soil moisture content to keep it at optimum level between $60-85 \%$. Moisture content below and above the range will prompt the solenoid vales to close and close respectively. It has to be noted that moisture content above $85 \%$ will not result in increase in production but rather ead to wastage of water and leaching of nutrients. Yield begins to decline when moisture content is less than $60 \%$. 


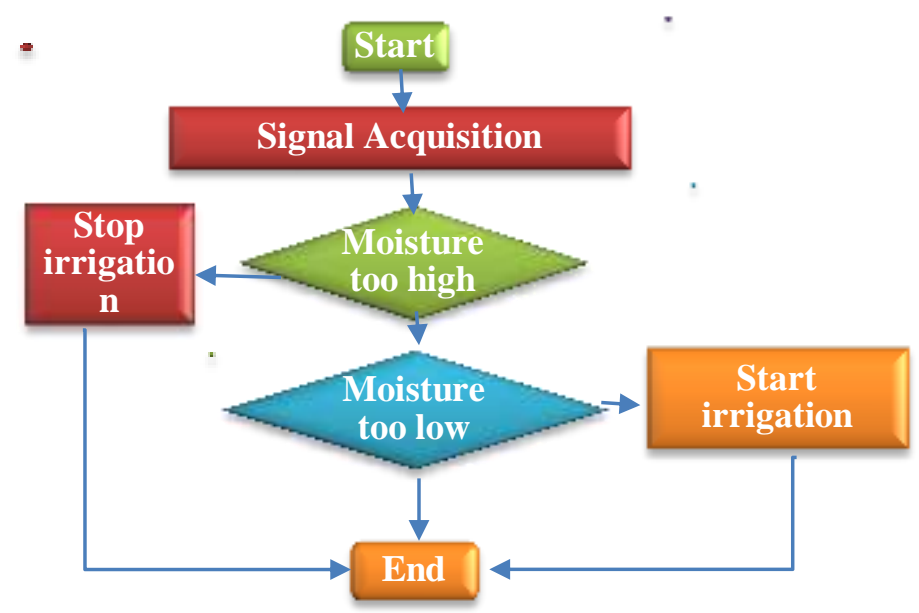

Figure 3:- Moisture Control Flow

\section{Experimental Design:-}

For the proposed project tomato seedlings of Clarisa, are to be planted into flat beds. The beds spaced were $1.5 \mathrm{~m}$ apart, center to center and seedlings were planted in rows with a spacing of $0.5 \mathrm{~m}$ between plants.

\section{Field layout:-}

This experiment is divided into four treatments. One of those treatments is time based scheduling while three are moisture based scheduling. Each of the treatment was composed of 2 replication. Each replication is 20m. The treatment are described in the Table $\mathbf{1}$ and a view of system layout below.

Table 1:- Treatments Showing Their Irrigation Scheduling Method

\begin{tabular}{|l|l|l|}
\hline Treatment & Scheduling Method & Device used \\
\hline A & Soil moisture based & Sensors \\
\hline B & Soil moisture based & Tensiometers \\
\hline C & Soil moisture based & Dielectric probe \\
\hline D & Time based & ETo based on historical weather data \\
\hline
\end{tabular}

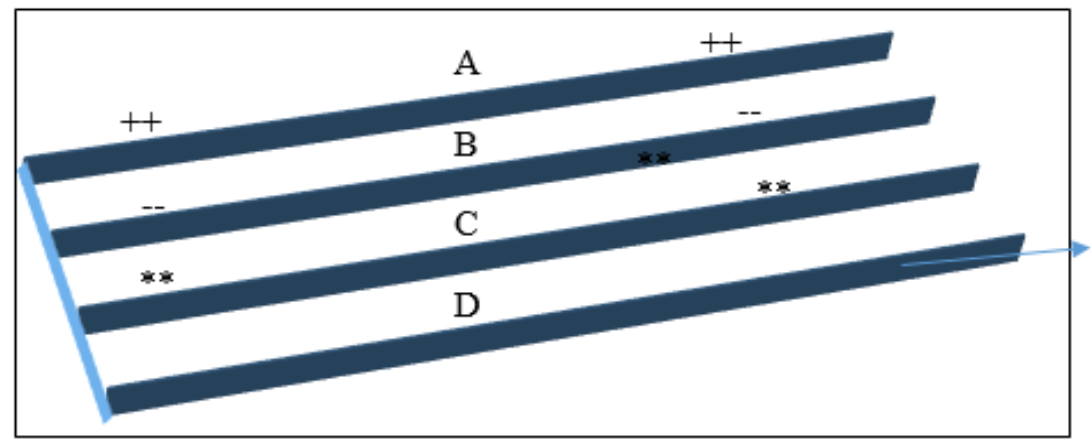

$$
\begin{array}{ll}
\text { Key } & \\
++ & \text { Sensors } \\
-- & \text { Tensiometers } \\
\text { ** } & \text { Dielectric probes } \\
\text { ETo based on historical } \\
\text { weather data }
\end{array}
$$

Figure 4:- Field layout

\section{Conclusion:-}

In order to promote sustainability in agriculture, particularly in the irrigation sector more research has to be done on measures that can save water and manage nutrient supply. More efficient technologies are beneficial in lowering the cost of production due to reduced pumping cost and leaching of nutrients. Fertigation allows easy manipulation of nutrients to meet plant needs. Plants can only absorb nutrients at a limited range of $\mathrm{pH}$ beyond that the nutrients become inaccessible. The use of power is a step toward achieving the SDG for using renewable environmentally energy. 


\section{References:-}

1. Alausa, D., \& Kolawole, K. K. (2013). Microcontroller Based Green House Control Device, 129-135.

2. Barsoum, N., \& Peter, A. (2015). GSM Greenhouse Monitoring and Control of Temperature and Soil Moisture, $4(6), 1-10$.

3. Burgess, J. (2006). Country Pasture / Forage Resource Profiles by.

4. Dhanure, S. P., \& Avatade, S. S. (2015). Irrigation System Using a Wireless Sensor Network and GPRS, 4(5). https://doi.org/10.17148/IJARCCE.2015.45111

5. Essah, E. A., \& Ofetotse, E. L. (2014). Energy supply, consumption and access dynamics in Botswana, 1-27.

6. FAO. (2015). FAO Statistical Pocketbook.

7. Gases, H. (2012). Agriculture and Food Security Policy Brief Reflecting on the Challenges of Attaining a Green Economy 1 for Botswana Botswana Agriculture Sector Policy Brief 2012, 1-7.

8. Gómez-melendez, D., López-lambraño, A., Ruiz, G. H.-, Rico-garcia, E., Olvera-olvera, C., \& Alanizlumbrerasc, D. (2011). Fuzzy irrigation greenhouse control system based on a field programmable gate array, 6(13), 3117-3130. https://doi.org/10.5897/AJAR10.1042

9. Hsing, C. C., Yu, C. G., \& Jenq, C. J. (2011). Greenhouse Environment System Based on Remote Control, 407410.

10. Jianjun, Z., Xiaofang, W., Xiu, W., Wei, Z., \& Jichen, C. (2013). Greenhouse Monitoring and Control System Based on Zigbee, (Iccsee), 2361-2364.

11. Madisa, M. E. (2012). Analysis of Horticultural Production Trends in Analysis of Horticultural Production Trends in Botswana, (January 2015). https://doi.org/10.5539/jps.v1n1p25

12. Rahali, A., Guerbaoui, M., Afou, Y. El, Tannouche, A., Lachhab, A., \& Bouchikhi, B. (2011). Development of a data acquisition and greenhouse control system based on GSM, 3(8), 297-306.

13. Salleh, A., Ismail, M. K., Mohamad, N. R., Aziz, M. Z. A. A., Othman, M. A., \& Misran, M. H. (2013). Development of Greenhouse Monitoring using Wireless Sensor Network through ZigBee Technology, 2(7), 612.

14. Schroder, J. H. (2006). Soil moisture-based drip irrigation for efficicent use of water and nutrients and sustainability of vegetables cropped on coarse soils. University of Florida.

15. STATISTICS BOTSWANA GROSS DOMESTIC PRODUCT. (2017).

16. Venkatraman, S., Kumar, L. D., Anish, E., Abinesh, V. X., \& Bennet, M. A. (2016). Solar Powered Automated Fertigation Control System for Terrace Farming Using Zigbee, 24, 401-407. https://doi.org/10.5829/idosi.mejsr.2016.24.TAET23347 